\title{
Research on Project Teaching Method in "Advanced Office Software Application" Course
}

\author{
Yingfang Zhang \\ Sino-Korean School of Multimedia Design \\ Shanghai University of Engineering Science, \\ Shanghai, China \\ zyfang0502@163.com
}

\begin{abstract}
The project teaching method is a kind of teaching mode with project contents as the center teaching. It creates the learning environment through selecting typical actual project, carries out the study and completes the project learning in the way of group collaboration, fully taps the creative potential of the students and improves their comprehensive ability to solve practical problems. Based on the analysis of the project teaching method and its characteristics, the paper describes specific practice of the method in "advanced office software application". The teaching practice shows that the project teaching method can train students' interest in learning, improve students understanding and master of the curriculum knowledge to achieve good teaching effect.
\end{abstract}

Keywords-project yeaching method, graduation thesis, office software, editing and layout design

\section{INTRODUCTION}

Office software is referred to the software of word processing, form making, power point, simple database processing and other aspects of the work, including Microsoft Office, WPS Office, and Red Office etc. These software applications are very extensive, so mastering the advanced features can greatly improve document quality and work efficiency. But in fact, $80 \%$ of the applications only master $20 \%$ of these software functions, which is the famous "two eight" phenomenon. The project teaching method is suitable for complex advanced office software application course teaching.

The project teaching method is a kind of teaching mode with project contents as the center teaching. It creates the learning environment through selecting typical actual project, carries out the study and completes the project learning in the way of group collaboration, fully taps the creative potential of the students and improves the students' comprehensive ability to solve practical problems. It aims to make the students own more active autonomous learning and construct knowledge and skill training through the learners' own practice.

The project teaching method emphasizes the students' main role, encourage students to take the way of selfeducation for acquires knowledge. This self-education includes three aspects: the students' collective self-education, the student' mutual education and individuals' self-education.

This paper is supported by the subject "research on the art-technology mode of digital media creative talents in Chinese foreign cooperative".ID: y201411001
The measuring scale of self-education is mainly the students actual participation and practical experience, and let the students comprehend the knowledge in the actual participation and experience to turn the knowledge into the students own knowledge through the teachers' summary and promotion. The project teaching method is based on the students autonomous and exploratory study, reflects the personalized and Hierarchical talent training concept, encourages and guides the students to carry on the research learning to make them go to the active development road in accordance with their own personality.

The project teaching method treats the actual project as its object. Firstly, the teacher decomposes the items, and makes an appropriate model; then the students carry on the discussion and collaborative learning in groups focusing on their respective projects; finally, the teacher assesses the students whether they have achieved the teaching purpose. The project teaching method is generally divided into 5 stages: project design, plan making, project implementation, result show, summary and evaluation.

In the teaching activities, teachers are the project designer. The teacher will provide problems or tasks, which will be solved or finished, to the students in the form of projects .Under the teacher's organization and guidance, the students will develop a plan in the way of team work according to the complete program of the actual work, to complete the whole project jointly or in division. The learning process becomes the creative practice for everyone to be involved in, focusing on the process of completing the project rather than the final result.

\section{APPLICATION OF THE PROJECT TEACHING METHOD}

The project teaching method is applied in the "advanced office software application" course teaching. This article takes the "editing and typesetting of long documents" as an example to make a detailed analysis and explanation.

\section{A. Project design}

The selected item is a graduation thesis editing and typesetting which each university student must experience. Project and task decomposition is as follows in table I . 
TABLE I. PROJECT AND TASK DECOMPOSITION

\begin{tabular}{|c|l|l|}
\hline \multicolumn{1}{|c|}{ Project } & \multicolumn{1}{|c|}{$\begin{array}{c}\text { Task } \\
\text { Decomposition }\end{array}$} & \multicolumn{1}{|c|}{ Covered Knowledge Points } \\
\hline \multirow{3}{*}{$\begin{array}{l}\text { Graduation } \\
\text { thesis } \\
\text { editing and } \\
\text { typesetting }\end{array}$} & Layout design & $\begin{array}{l}\text { Page setting, view method, } \\
\text { separation method, the page } \\
\text { header and footer page } \\
\text { numbers }\end{array}$ \\
\cline { 2 - 3 } & Style settings & $\begin{array}{l}\text { Style, document notes, cross } \\
\text { references, catalogue and } \\
\text { index. }\end{array}$ \\
\cline { 2 - 3 } & Document revision & comments, revision \\
\hline
\end{tabular}

The selection of the project is in line with students' actual needs. It introduces the simulated graduation thesis as a project not out of touch with reality, raises the students interest and will provide a lot of help for their future learning and work. Secondly, the project has a certain complexity and strong inspiration, contains a certain depth, leaves more thinking space, can inspire thinking, and maximizes the teaching effect. Thirdly, the project is very typical. The items reflect the general characteristics of the editing and typesetting of a long document and play an important role. Fourthly, the project has a purpose. The project selection adapts to the teaching purpose and requirement and can improve students' comprehensive ability of problem analysis and problem solving.

\section{B. Project plan making}

Create the context. Through creating the actual environment that students write graduation thesis in the fourth year of the university, the teacher leads students into a situation of solving the practical problems to make the students think in an intuitive and emotional environment. Combined with demonstration of small examples, the teacher raises students' imagination and creativity, improve their learning enthusiasm.

Group the students according to the learning situation and personal opinions. 35 students are divided into 7 groups, 4-6 in one group and each group elects a leader. The group uses the cooperative learning mode, for example, the group leader is in overall charge of the team learning discussion and the arrangement of the project, including the task division in a team, time progress schedules, extracurricular learning, discussion and communication, supervision and inspection, summary results, show reply and so on. The labor division and cooperation learning can make students display their respective strengths and advantages.

The teacher clarifies the method and requirement of learning methods, contents requirement, a reference, progress requirements, process record, extra-curricular learning, the final results show, and comprehensive evaluation. The teacher guides students to clarify the objectives, tasks and responsibilities, encourages students to explore boldly and trains the students for good communication and good cooperation ability and their team cooperation spirit. Through the timely inspection activity recording and stage results to evaluation and regulation, the teacher ensures that students participate actively and effectively in the learning process and improve students' learning efficiency and enhance learning effects.

\section{Implementation of the project}

In this period, the group cooperation is the basic form of organization and activities. At the beginning of the implementation, the teacher needs to give more specific guidance to the discussions of each group focusing on the project, refine the task, clarify the labor division and the task completion situation.

In the project implementation process, the team members complete the task with the principle of joint exploration and mutual cooperation. The students make use of all the resources of curriculum learning, construct good knowledge acquisition and skill training network, carry out cooperative interactive learning, understand what is learned and exchange the learning achievements. The mechanism of competition is formed among different project teams. The work efficiency, knowledge application, problem solving ability, skill enhancement, teamwork and innovation ability of the project team are all considered as the assessment index of the project group. The teacher is a participant to lead the students think and explore, practice, understand, master and use knowledge in practice step by step. When students encounter difficulties, first of all, the students are encouraged to have mutual discussion, including the discussion between students and between teachers and students, to look up relevant information and documents to seek the answers to the questions and the methods to solve the problems. For individual problems, the teacher gives patient counseling and explanation; for common problems, teachers focus on teaching. The students need the teacher's help sincerely from the bottom, which can make an immediate teaching effect.

\section{D. results display}

The representative of each group reports the situations of group personnel, task divisions, Literature review, completion degree, shows the final results of the group, lists the problems in the process of the project completion, as well as the problem-solving process and method to the whole class in the form of presentation and answers the questions asked by teachers and students from other groups.

Teachers play the role of organizers during this period. Students play the role of demonstration, explanation and appreciation. Students present their project results on the stage show, appreciation and study the works of others, to find their own deficiencies.

\section{E. A summary and evaluation}

The evaluation on each student is determined on the three levels of comprehensive evaluation: the first level is that the teacher determines according to the project completion of the group ;The second level is that the team members evaluate each other according to the contribution of members; The third level is that the students evaluate themselves.

The standard of evaluation emphasizes on whether the students really grasp new knowledge and skills and whether they can have a profound understanding and flexible 
application on the new knowledge and skills in the process of completing the tasks.

Teachers' comment is an important link of project teaching method. The teacher gives a comprehensive evaluation according to the students collected information, participation degree, the role they played, cooperation ability, project reports and each group' s final results report and display effect, answering questions and the cooperation spirit among members of a group in the activities. It is very important to emphasize the knowledge system and the key points and difficulties, further study and research the issues, fully affirm the advantages, and clearly put forward the existing problems and shortcomings and improvement advice, especially pay attention to correcting the universal error.

Students' evaluation includes two aspects. One is the students' self-evaluation. The students sum up what they have learned from the project and what are the gaps and deficiencies and pay attention to what issues should be paid attention while doing similar projects in the future. The other is to carry out mutual communication between team members to peer review. Members of the group will assess each other about work completion situation, the difficulty and works, cooperative attitude, the spirit of cooperation of mutual evaluation etc.

The evaluation content, standard, and corresponding grades and scores are in the following table II .

TABLE II. EVALUATION CONTENTS, STANDARDS AND THE CORRESPONDING RANK

\begin{tabular}{|c|c|c|}
\hline $\begin{array}{c}\text { Evaluation } \\
\text { Content }\end{array}$ & Evaluation Standards & $\begin{array}{c}\text { Corresponding } \\
\text { Grades and Scores }\end{array}$ \\
\hline $\begin{array}{l}\text { task } \\
\text { completion } \\
\text { situation } \\
(50)\end{array}$ & $\begin{array}{l}\text { Style setting and modification } \\
\text { of all levels titles } \\
\text { Automatically numbers of titles } \\
\text { of all levels } \\
\text { Mixed arrangement of graphics } \\
\text { and text :graph, table, formula } \\
\text { The caption and cross reference } \\
\text { Catalog and index } \\
\text { The layout effect }\end{array}$ & $\begin{array}{l}\text { excellent(A): } 45 \sim 50 \\
\operatorname{good}(B): 40 \sim 44 \\
\text { middle(C): } 35 \sim 39 \\
\text { passed(D): } 30 \sim 34 \\
\text { failed(F): }<30\end{array}$ \\
\hline $\begin{array}{l}\text { comprehensive } \\
\text { use of } \\
\text { knowledge } \\
(30)\end{array}$ & $\begin{array}{l}\text { The flexible application of all } \\
\text { kinds of knowledge points }\end{array}$ & $\begin{array}{l}\text { excellent(A): } 27 \sim 30 \\
\text { good(B): } 24 \sim 26 \\
\text { middle(C): } 21 \sim 23 \\
\text { passed(D): } 18 \sim 20 \\
\text { failed(F): }<20\end{array}$ \\
\hline $\begin{array}{l}\text { team } \\
\text { cooperation } \\
(20)\end{array}$ & $\begin{array}{l}\text { Cooperative attitude } \\
\text { Communication ability }\end{array}$ & $\begin{array}{l}\text { excellent(A): } 18 \sim 20 \\
\text { good(B): } 16 \sim 17 \\
\text { middle(C): } 14 \sim 15 \\
\text { passed(D): } 12 \sim 13 \\
\text { failed(F): }<12\end{array}$ \\
\hline
\end{tabular}

The goal of the project teaching method is that every student can master the editing and layout of long documents such as graduation thesis. Thus as the teaching achievements inspection, it is required that every student select a topic, and collect literature according to their own interests and professionals, edit and typeset according to requirements of the graduation thesis to submit the teacher evaluation as a big stage homework. Seen from the complex homework, students are able to use long document knowledge to finish the editing and composing of the graduation thesis on their own with high efficiency. The quality conforms to the requirements of universities. The results show that the project teaching effect is effective and good, and at the same time it also obtains the affirmation of graduation thesis guidance teacher.

\section{CONCLUSION}

Project teaching combines knowledge, quality, ability education, and helpful to students learning knowledge, dedication and devotion, teamwork, innovation ability. There is an organic combination and comprehensive reflection in the interactive process. The implementation of the project teaching method in the teaching not only enhance the students practical ability, thinking ability, research ability, innovation ability and social ability, but also build an open and research learning environment, so that students have enough space to carry on the research learning in their own way. The students can achieve the acquisition and mastery of the knowledge and skills by solving some problems in the project and greatly improve the students learning enthusiasm and independence.

The teaching practice shows that the project teaching method can train students' interest in learning, improve students understanding and master of the curriculum knowledge to achieve good teaching effect, which has a good reference value for the practical course.

\section{References}

[1] Zhu Cuihong. Research on Project Teaching Method of Network Marketing Professional Curriculum [J]. Journal of Huazhong Normal,2014,4(3)

[2] Liu Haipeng. Course Teaching Based on Project Teaching Method in "Webpage Design and Making"[J]. China CIO News,2014,01:157-158.

[3] Chen Hongjie, Li Yan. Application of Project Teaching Method in "Flash Animation Design"[J].Science \& Technology Information, 2012 03:237.

[4] Xu Zhaojie. Comparison of Task Driving Teaching Method and Project Teaching Method[J].Education and Vocation, 2008, 11:36-37.

[5] Song Zhaoxia, Yu Qiding. Research on Project-based Teaching Model Based on Flipped Classroom [J]. Distance Education Journal, 2014, 01:96-104.

[6] ZHANG Lan-fang. Basic Teaching of Computer and the Evaluation Based on the Project Based Learning [J].Journal of Southwest China Normal University (Natural Science Edition),2012, 37(6)

[7] Li Yingwu, Application of Project Teaching Method in Teaching [J],Education Exploration,2008, 3(4) 